\title{
The Influence of Information Technology on Student's Behavioural Nature in the Class Room
}

\author{
Liaqat Ali ${ }^{1}$ \\ 'Ajman University, Fujairah, UAE \\ Email:Liaqat22@gmail.com Tel:00971501510587
}

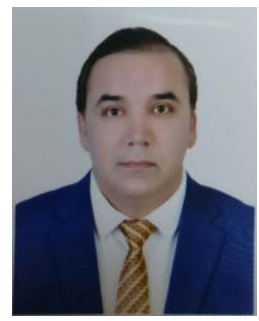

\begin{abstract}
The use of mobile phones and other gadgets in the university class room is becoming a culture in the modern age of technology. Some students use this technology for the purpose of information only. However, it was noted that others use mobile phone to receive messages through different applications such as WhatsApp, Facebook, Instagram and Viber. It is therefore important to understand the impacts of their behaviour. On the other hand, the use of mobile technology effects the teaching strategies. Teachers need to adopt new teaching methodologies to make sure that educational objectives and student's deep learning could be achieved together. It is therefore critical to adopt a balance approach. The research in this paper conducted a survey to find the relationship between student's behaviour and the use of mobile technology. The analysed data is used to balance the approach and to achieve educational objectives.
\end{abstract}

Keywords: Information Technology, Mobile apps, Class room, Teaching, Students, Educational objectives.

Citation | Liaqat Ali (2018). The Influence of Information Technology on Student's Behavioural Nature in the Class Room. Asian Journal of Education and Training, 4(2): 102-107. History:

Received: 2 November 2017

Revised: 2 March 2018

Accepted: 5 March 2018

Published: 7 March 2018

Licensed: This work is licensed under a Creative Commons

Attribution 3.0 License $(\mathrm{cc})$

Publisher:Asian Online Journal Publishing Group

\section{Contents}

1. Introduction

Funding: This study received no specific financial support.

Competing Interests: The author declares that there are no conflicts of interests regarding the publication of this paper.

Transparency: The author confirms that the manuscript is an honest, accurate, and transparent account of the study was reported; that no vital features of the study have been omitted; and that any discrepancies from the study as planned have been explained.

Ethical: This study follows all ethical practices during writing.

2. Statement of the Problem ................ 103

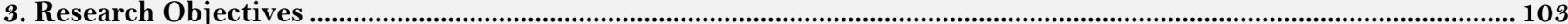

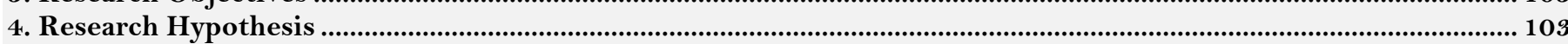

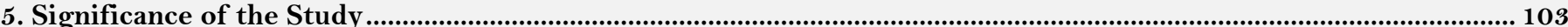

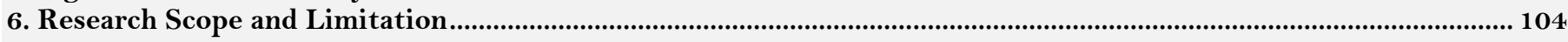

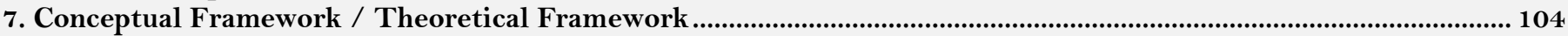

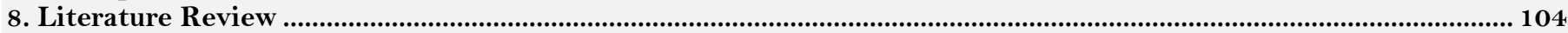

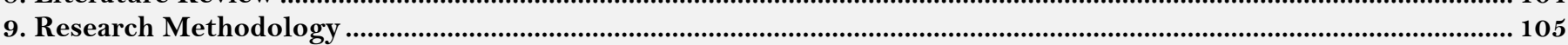

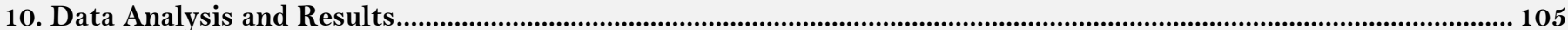

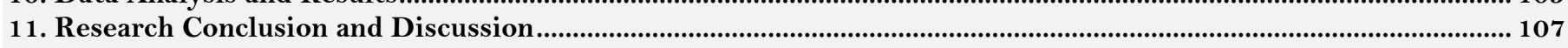

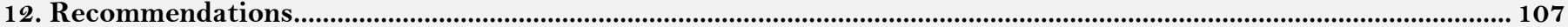

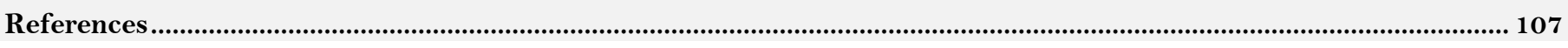




\section{Introduction}

The role of internet in education is important because it provides instant access to available information around the world. Education could be provided remotely across the world through the medium of internet and its resources. Traditional learning and teaching processes are changing due to the plethora of information available through internet resources. Teachers and learns both have instant access to the information on virtually any subject.

The rapid development of internet resources and its availability to conduct leaning in virtual environment lead students and teachers to adopt new mechanisms and techniques during the process learning and teaching.

In many classrooms across universities and colleges students bringing and using their gadgets and mobile phones are affecting learning processes. It is obvious that learners may use the technology for information related purposes during learning processes in the class rooms. However, some students may use mobile technology and other gadgets to communicate with friends and families through available social applications and other networking sites. Due to this, the author of this research became interested in findings the behaviours of the students in the class room environment. Also, the researcher is interested that how this behaviour of students affects the teaching methodologies of the teachers and how this could be balanced when teaching in class rooms. The author is interested to find out that how the use of mobile technology and social networking applications effect student's learning process.

Research has shown that the use of mobile technology is a great experience for students during the provision of teaching. Mobile technology could be used for efficiency and effectiveness while collecting information from the web. Students could use mobile technology for audio recording purposes in the class room. This is how they record teacher's lectures and this further helps students to learn in effective ways. Mobile technology is a great tool for the live polling, if the class room strength is heavy. This will help teachers to understand student's thinking and effective teaching could be delivered through this process.

\section{Statement of the Problem}

\subsection{General}

Students using mobile phones and other gadgets certainly effect the way of teaching and learning during class room environments. In universities, it is becoming a fashion or culture to use mobile and other electronic gadgets. Students frequently use mobile applications during the process of teaching and learning. This behaviour leads to harm the process of teaching and learning. A balance approach is therefore required to make sure that educational objectives could be achieved.

\subsection{Specific}

1. There is a crucial need to adopt new teaching methods to balance the use of mobile technology and teaching objectives.

2. it's important for educational organizations to maximize the use of information technology and to use all existing tools and gadgets to achieve educational objectives.

\section{Research Objectives}

This research is based on the following objectives;

- To critically investigate the use of information technology and its applications in education especially in the class room environment.

- $\quad$ To understand the effects of information systems and technology on student's behaviour

- To investigate the new teaching methodologies that can balance learning and teaching processes through the use of information system and technology and its available applications.

- To recommend an approach that could balance the learning and teaching processes through the use of information system and technology.

\section{Research Hypothesis}

The research is based on the following 6 major hypothesis;

H1- The use of mobile technology and its applications got positive impacts on student's academic performance.

H2- The use of mobile technology and its applications got negative impacts on student's academic performance.

H3- The use of mobile technology and its applications got positive impacts on student's behaviour in class room environment.

H4- The use of mobile technology and its applications got negative impacts on student's behaviour in class room environment.

H5- The use of mobile technology and its applications got positive impacts on teaching strategies in class room environment.

H6- The use of mobile technology and its applications got negative impacts on teaching strategies in class room environment.

\section{Significance of the Study}

The significance of this research could be measured by the effective outcomes and recommendations made in this research to improve the effectiveness of teaching and learning processes in the class room environments. The conducted research would be beneficial for educational industry especially for teachers in higher education facing problems with students due to the use of their gadgets during the delivery of their lectures in the class room environments. Further, the research would benefit the universities in the policies of teaching and learning, looking to develop new approaches that could balance the approaches of learning process between teachers and learners. The research will provide a comprehensive reading for universities students to understand the importance of mobile 
technology and other gadgets and will provide them guideline on how to effectively use them while the provision of teaching and learning.

\section{Research Scope and Limitation}

The conducted research will be useful for the education industry as it will help teachers to adopt new teaching techniques and methodologies in the class room environment and to balance to use of information technology and systems. The research is also beneficial to understand the behaviour of the students due to the impacts of the technology and information systems in education. The scope of the research could be measured through the scope of information technology and its use in the educational environment. Time and available resources could be the possible limitations of this research.

From academic and educational point of view, the research will provide a comprehensive approach adopted to understand the use of mobile technology and its role in the education especially in the class room environment.

From social aspect, the research will provide an opportunity to understand the behaviour of students and its relationship with technology during the provision of teaching and learning.

The scientific value of the research will be the outcomes in the form of recommendations that would be helpful to balance the use of mobile technology and new teaching methodologies to achieve educational objectives.

\section{Conceptual Framework / Theoretical Framework}

This research follows the following conceptual/ theoretical framework.

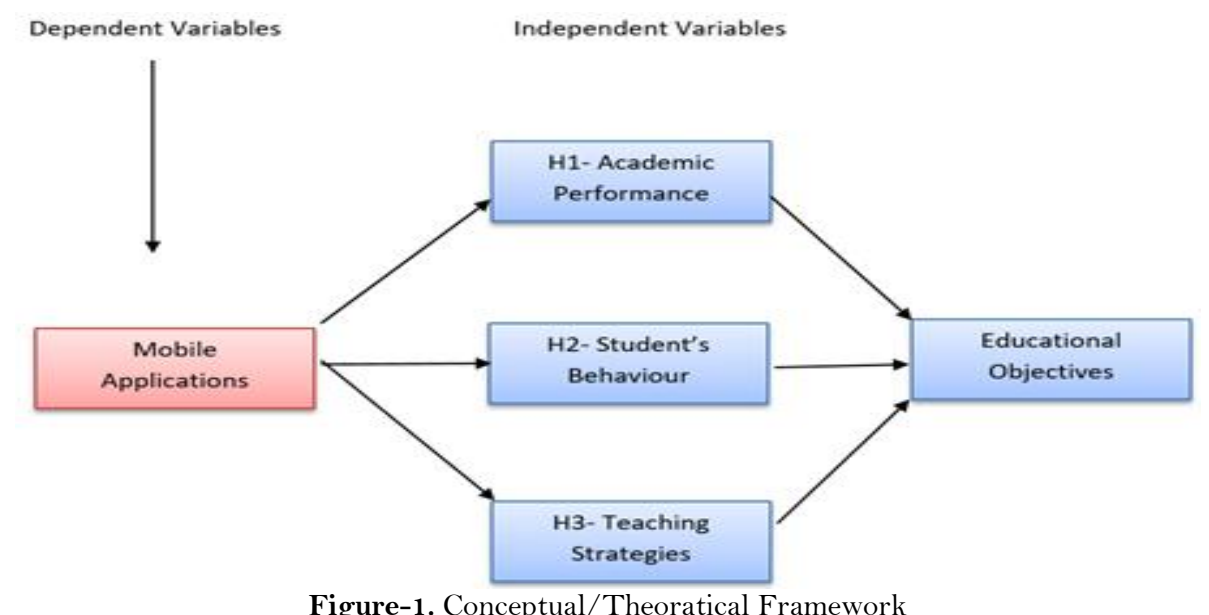

\section{Literature Review}

One of the biggest challengers teachers face nowadays in classroom is related to retaining the interest of student in classes while students have the option to remain connected to the virtual world using their smart phones. It is one of the biggest debates as to whether these devices affect the academic performance of students or not. It's time for the college faculty to accept that students will bring their mobile device with them to class. The important factor that needs to be considered is the impact of these devices on learning process.

A number of researchers have conducted research on the impact of technology and its usage on academic achievement. According to a study Jeffrey et al. (2015) it was found that the students who are constantly using mobile phones are outperformed by students who abstain from that. The study also concluded that frequent messaging which were not related to class content interferes with student learning while in class.

Numerous studies have also been conducted to find the relationship between academic performance, educational objectives and the use of social networking sites. According to the paper (Kirschner and Karpinski, 2010) it was found that learners who spent additional time on Facebook usually have lower GPA compared to others. Another study Junco (2012) conducted in the same area found out that the time spent on Facebook was strongly and significantly related to overall GPA while only weakly related to time spent preparing for class. It was also found that using Facebook for collecting and sharing information was positively predictive of the outcome variables, while using Facebook for socializing was negatively predictive (Junco, 2012).

Research studies have also pointed out that multitasking as one of reason for negative relationship between electronic media use and academic performance. A recent study Wood et al. (2012) measured the influence of multitasking with a collection of electronic media on the student's ability to learn from lectures in University. Mobile phone, messenger, emails and texting through available social media network sites are the four digitally based multi-tasking activities which were compared to three control groups (paper-and-pencil note-taking, wordprocessing note-taking and a natural use of technology condition) over three consecutive lectures. It was found that the students multitasking with these technologies were linked with lower grades on tests compared to students who don't multitask (Saraswathi et al., 2015). Another study Junco and Cotton (2012) used hierarchical regression to analyse the impact of multitasking to College GPA. It was found that multitasking may affect the capacity for cognitive processing and prevent deeper learning. According to another study Rosen et al. (2011) it was found that students who received more text message interruptions during a class suffered in terms of their marks. Research was also done to study the impact of technology-based multitasking behaviours inside and outside classrooms. The study demonstrated that students who multitask frequently in class have lower GPA. The relation remained significant even when the perceived multitasking efficiency and time spent studying outside of class was controlled. It was also found that those students who multitasked while doing their academic work used up additional time studying outside of class, which meant unproductive study behaviours. 
Based on the available research, it shows that there is strong link between the usage of mobile phones and academic performance.

\section{Research Methodology}

The methodology of this research adopted both qualitative and quantitative approach and has conduct a student's survey to understand the relationship among their behaviour and the use of mobile technology in the class room environments. The research used both primary and secondary data resources to accomplish the results. For the purpose of primary data, a research questionnaire was developed and distributed among the students of the University for both undergraduate and postgraduate level. Data was collected and was further analysed with the help of SPSS. A total of 350 students both from undergraduate and postgraduate participated in the survey. The results were compiled based on the scale of Strongly Agree, Agree, Not Agree not Disagree, Disagree and Strongly Disagree from male and female students with undergraduate and postgraduate students of different age groups. Following are the questions statements asked during the survey of this research.

a) I always use a mobile phone in class during the process of teaching.

b) I like to chat with friends/family through a mobile device during class time

c) I share information in class through WhatsApp, Viber, Email, Text Message or Other.

d) I like to browse the following apps in class timings

e) I use mobile because I feel the teacher/lecturer is boring

f) It is the students' rights to use mobile devices whenever they want.

\section{Data Analysis and Results}

a) I always use a mobile phone in class during the process of teaching.

Figure 2 shows the relationship between gender and mobile usage during the process of teaching in the classroom. Both males (19.2\%) and females (31.3\%) are uncertain on whether or not to use a mobile phone in class rooms during the delivery of lectures. However, males are more inclined towards using a mobile phone in class. On the other hand, females are more inclined towards not using a mobile phone in class.

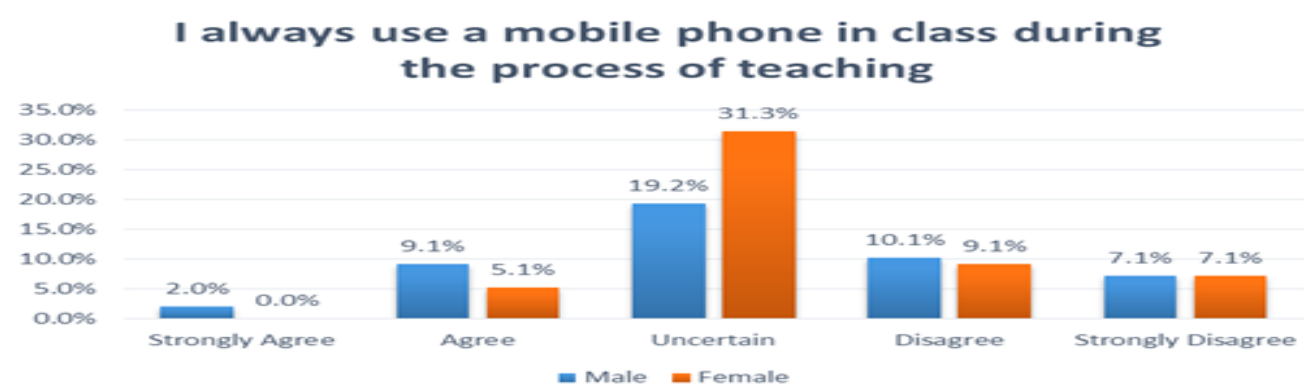

Figure-2. Relationship between gender and mobile usage in class

b) I like to chat with friends/family through a mobile device during class time

The response of males and females regarding chatting with friends and family through a mobile device during class is conveyed in Figure 3 below. The results show that $22.2 \%$ females are uncertain, while $19.2 \%$ disagree and $9.1 \%$ are strongly disagree. In the case of the male percentage, $14.1 \%$ disagree and $12.1 \%$ are strongly disagree with the statement. Only $1 \%$ male students strongly agree, however, further $8.1 \%$ students accepted or agreed that they are using mobile devices to chat with their friends and families during the process of lecture delivery in class rooms. Out of 350 respondents, only $2 \%$ female agreed with statement of this question.

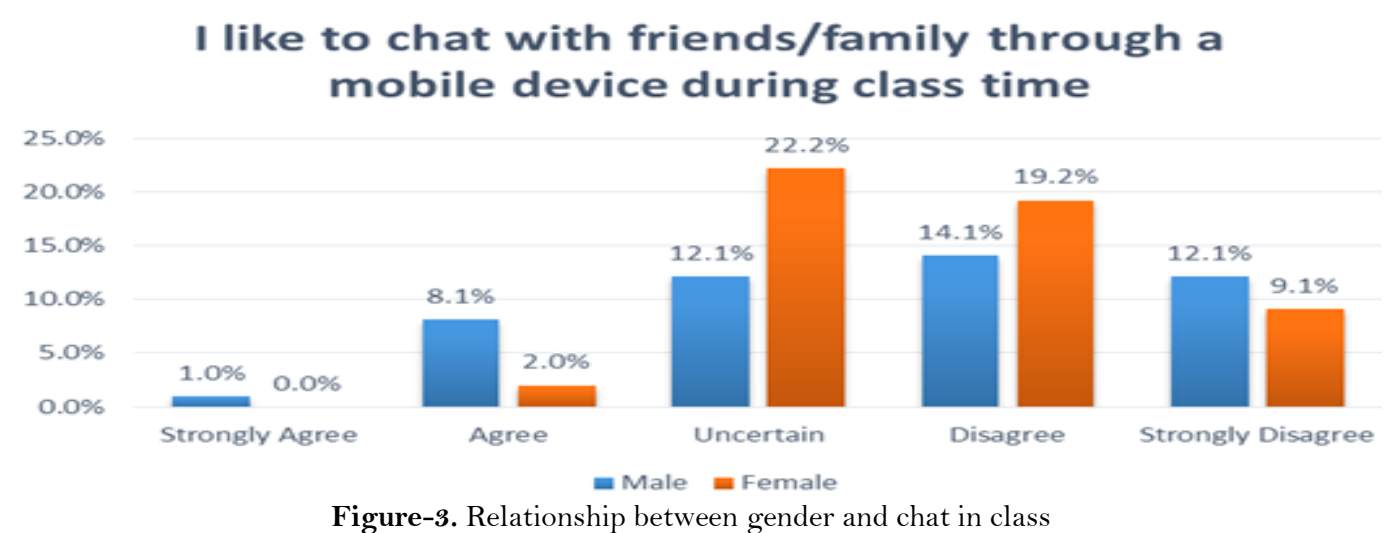

c) I share information in class through WhatsApp, Viber, Email, Text Message or Other.

The relationship between gender and sharing of information in class is reported in Figure 4. WhatsApp is considered by both male $(39.1 \%)$ and female $(31.5 \%)$ as the most common method of sharing information in class, followed by email. 
I share information in class through....

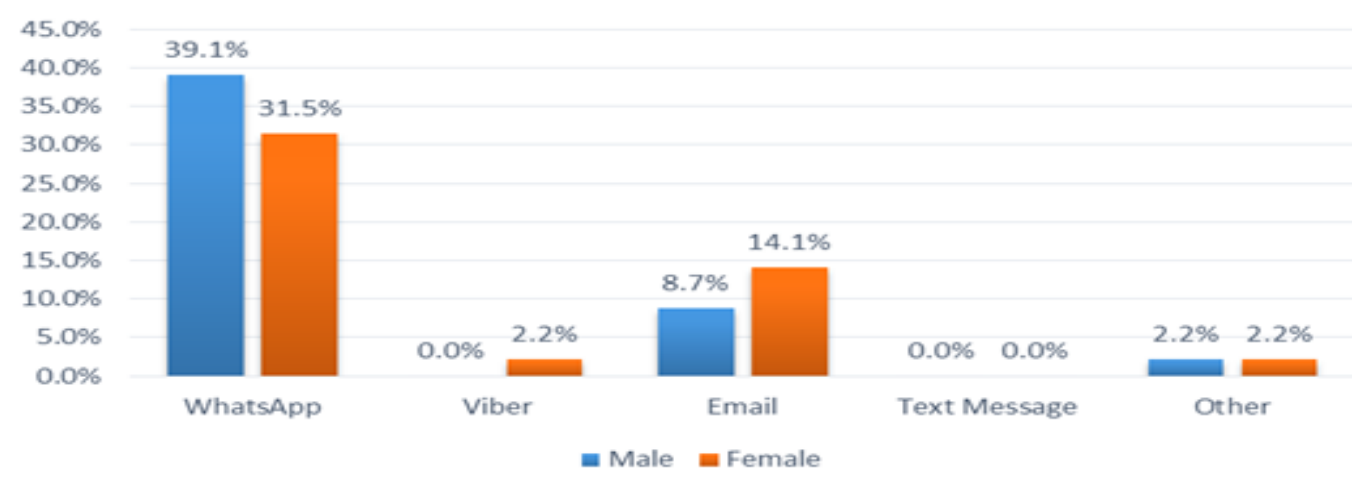

Figure-4. Relationship between gender and sharing information in class

\section{d) I like to browse the following apps in class timings}

Figure 5 shows the relationship between program (undergraduate and graduate) level and browsing in class time by students. Instagram is indicated as the major browsing app during class time by $51.1 \%$ of undergraduate and $4.3 \%$ graduate students. $5.3 \%$ undergraduate and $3.2 \%$ graduate students accepted the use of Facebook application. $8.5 \%$ undergraduate students agreed with the use of Twitter application. However, graduate students $(7.4 \%)$ respond with other apps during class for browsing.

The analysis proves that undergraduate students are more motivated to browse data and other applications during the delivery of lectures in class room environments. The graduate or postgraduate students are motivated to concentrate more on the lecture delivery of their teachers.

On the other hand, the analysis of collected data proved that the application of Instagram is more famous among students compare to Facebook, Twitter and other applications available on the platforms of social media. More than $51 \%$ undergraduate students agreed with the use of Instagram application.

\section{I like to browse the following apps in class timings}

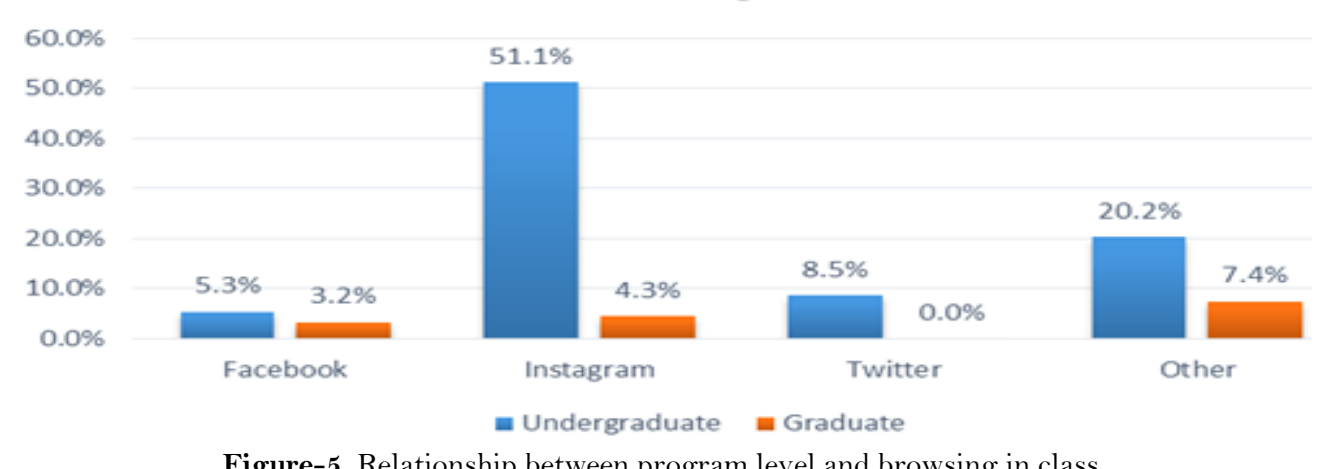

Figure-5. Relationship between program level and browsing in class

\section{e) I use mobile because I feel the teacher/lecturer is boring}

The relationship between mobile usages because teacher/lecture is boring and different age groups of student is reported in Figure 6. Younger students are more uncertain, while elder students strongly disagree with the statement.

As per Figure 6 below, young students between the ages of 18-25 strongly agree (4.2\%) and agree (13.5\%) that they use mobile during the course of lecture delivery and feels that their lesson or teacher is boring. This further proves that teachers need to concentrate more on students of young ages to make sure that they can fully concentrate on the process of lecture delivery in class room environments.

\section{I use mobile because I feel the teacher/lecturer is boring}

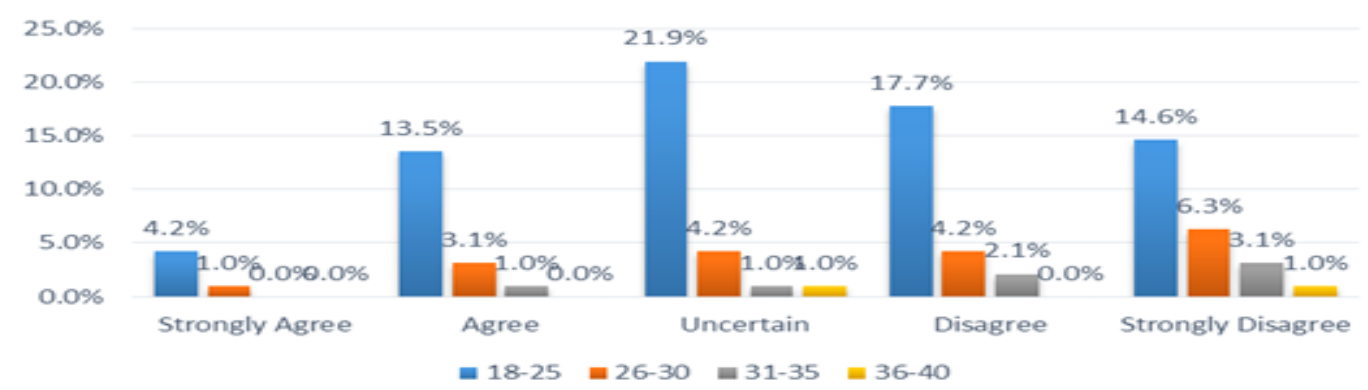

Figure-6. Relationship between age group and lecture

f) It is the students' rights to use mobile devices whenever they want.

Figure 7 shows the relationship between different age groups and the rights of students to use mobile devices whenever they want. Younger students (18-25) agree with the statement (28.9\%) and (4.1\%) strongly agreed, and $(21.6 \%)$ were found uncertain with the statement. $12.4 \%$ students of the same age group (18-25) disagreed while $4.1 \%$ strongly disagreed with the same statement.

Further, the analysis proves that the age group 26-30 is uncertain with the statement (9.3\%). 


\section{It is the students rights to use mobile devices whenever they want}

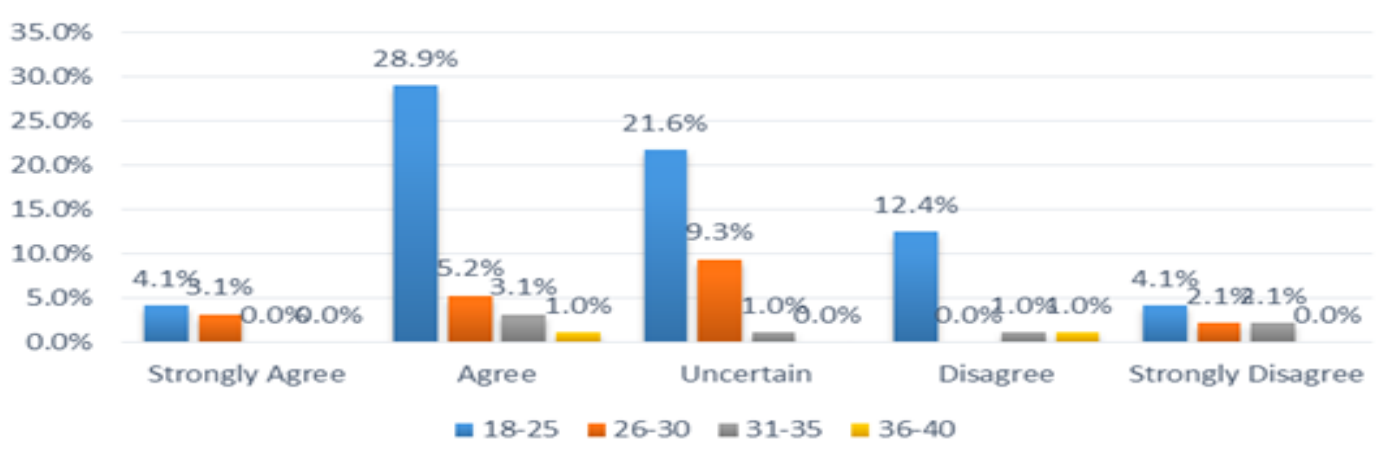

Figure-7. Relationship between age group and rights of the students to use mobile devices.

\section{Research Conclusion and Discussion}

The conducted research proved that there is a strong relationship between the use of mobile technology and student's behaviour. Certainly, the use of mobile applications and technology effects students' behaviour, academic performance and teaching strategies. Alternatively, the educational objectives got a direct link between with the use of mobile technology in the class room environments. It is impossible to stop students from using mobile during the course of lecture deliver and therefore teachers need to adopt new techniques and methodologies to balance this and overcome issues raised due to the use of mobile applications.

It is equally important to look on the behaviour of teachers who use mobile technology during the course of their lecture delivery. In a survey conducted by Pew Research Centre in United Sate of America was found that 73\% of the teachers reported using mobile technology in their classrooms, either through their own instruction or by allowing students to use it to complete assignments (Pew Research Centre, 2015). The world of e-leaning in higher education is in transformation and we need to benefit from the available information technology and applications. This is the responsibility of the teachers to make sure and balance the use of information system and technology during the course of their lecture delivery in class room environments.

\section{Recommendations}

Based on the data analysed, this research recommends the following to balance the course of lecture delivery and the use of mobile technology among university students;

- E-Readers should be introduced in class rooms to balance the approach and also to benefit from the latest information available over the internet compare to traditional books where much of the information is outdated.

- Universities and higher educational class rooms should be more equipped with the available latest information technology to motivate students to deep learning process.

- Teachers should motivate students to use information technology positively for educational purpose in class room environment.

- Social media and its applications should be adopted by teachers during the course of their lecture delivery.

- Creative teaching should be adopted in universities and higher educational institutions with the help of creative tools to stimulate creativity.

- There is need to incorporate audio and visual materials during the course of lecture delivery to motivate students to concentrate on their educational objectives rather than using their mobile applications without any educational purpose.

Universities and higher educational institutions need to consider on how educators/lecturers can become more skilled in learning design and delivery with the help of information technology and mobile applications to maximize student's learning process and to achieve educational objectives.

\section{References}

Jeffrey, K.H., M. Stevie and T. Scott, 2015. Mobile phones in the classroom: Examining the effects of texting, twitter, and message content on student learning. Communication Education, 64(3): 344-365. View at Google Scholar $\mid$ View at Publisher

Junco, R., 2012. Too much face and not enough books: The relationship between multiple indices of facebook use and academic performance. Computers in Human Behavior, 28(1): 187-198. View at Google Scholar | View at Publisher

Junco, R. and S.R. Cotton, 2012. No A 4 U: The relationship between multitasking and academic performance. Computers \& Education, 59(2): 505-514. View at Google Scholar | View at Publisher

Kirschner, P.A. and A.C. Karpinski, 2010. Facebook and academic performance. Computers in Human Behavior, 26(6): 1237-1245. View at Google Scholar | View at Publisher

Pew Research Centre, 2015. Do mobile devices in the classroom really improve learning outcomes? The Conversation, Academic Rigour, Journalistic Flair.

Rosen, L.D., A.F. Lim, L.M. Carrier and N.A. Cheever, 2011. An empirical examination of the educational impact of text message-induced task switching in the classroom: Educational implications and strategies to enhance learning. Psicologia Educativa, 17(2): 163-177. View at Google Scholar | View at Publisher

Saraswathi, B., N.L. Kristine and H.S. Kyle, 2015. Make it our time: In class multitaskers have lower academic performance. Computers in Human Behavior, 53: 63-70. View at Google Scholar $\mid$ View at Publisher

Wood, E., L. Zivcakova, P. Gentile, K. Archer, D. De Pasquale and A. Nosko, 2012. Examining the impact of off-task multi-tasking with technology on real-time classroom learning. Computers \& Education, 58(1): 365-374. View at Google Scholar |View at Publisher 